
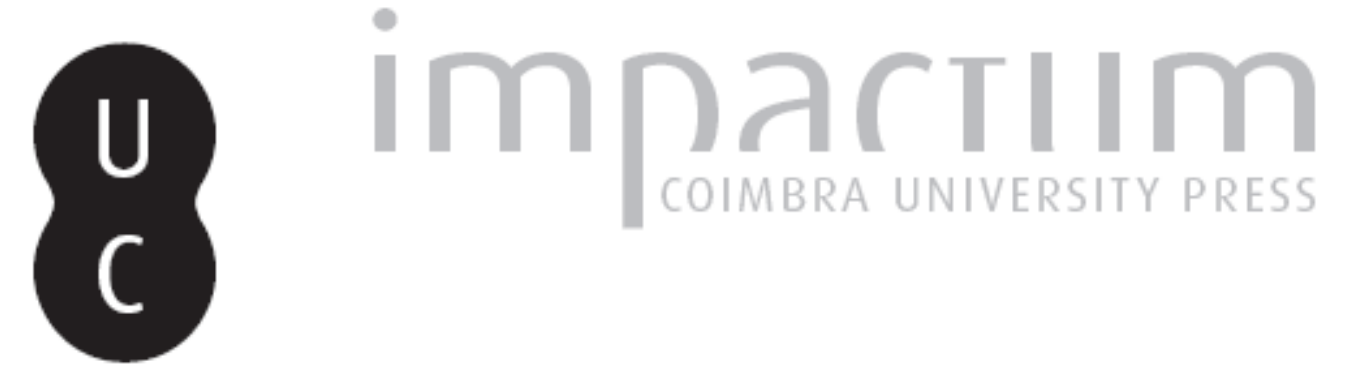

\title{
Avaliação e reparação do dano patrimonial e não patrimonial (no domínio do Direito Civil)
}

Autor(es): $\quad$ Dinis, Joaquim José de Sousa

Publicado por: Imprensa da Universidade de Coimbra

URL persistente:

URI:http://hdl.handle.net/10316.2/33291

DOI:

DOI:http://dx.doi.org/10.14195/1647-8630_19_2

Accessed : $\quad$ 26-Apr-2023 13:44:24

A navegação consulta e descarregamento dos títulos inseridos nas Bibliotecas Digitais UC Digitalis, UC Pombalina e UC Impactum, pressupõem a aceitação plena e sem reservas dos Termos e Condições de Uso destas Bibliotecas Digitais, disponíveis em https://digitalis.uc.pt/pt-pt/termos.

Conforme exposto nos referidos Termos e Condições de Uso, o descarregamento de títulos de acesso restrito requer uma licença válida de autorização devendo o utilizador aceder ao(s) documento(s) a partir de um endereço de IP da instituição detentora da supramencionada licença.

Ao utilizador é apenas permitido o descarregamento para uso pessoal, pelo que o emprego do(s) título(s) descarregado(s) para outro fim, designadamente comercial, carece de autorização do respetivo autor ou editor da obra.

Na medida em que todas as obras da UC Digitalis se encontram protegidas pelo Código do Direito de Autor e Direitos Conexos e demais legislação aplicável, toda a cópia, parcial ou total, deste documento, nos casos em que é legalmente admitida, deverá conter ou fazer-se acompanhar por este aviso.

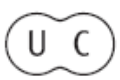




\section{Avaliação e reparação do dano patrimonial e não patrimonial (no domínio do Direito (ivil) ${ }^{1}$}

Joaquim José de Sousa Dinis²

\section{Introdução}

No âmbito da avaliação dos danos patrimoniais e não patrimoniais, no Direito Civil, sobretudo quando decorrentes de acidentes rodoviários, alguns há em que os juízes sentem dificuldades na sua fixação para efeitos indemnizatórios. É o caso dos danos futuros e dos danos não patrimoniais. E muitas vezes encontram-se soluções indemnizatórias díspares para situações semelhantes.

Daí que a jurisprudência, ao longo dos anos, venha tentando encontrar um rumo orientador que evite tais divergências. E no entanto, a solução estava bem perto, já que países que nos são próximos, com uma matriz sócio-cultural e linguística semelhante, haviam resolvido problemas idênticos estabelecendo tabelas de incapacidade ou "barèmes". Grosso modo, através delas o médico legista pontua o ou os danos corporais de forma a determinar o grau de incapacidade, após o que o conjunto de pontos ou este grau é transformado em indemnização, por indexação a um determinado parâmetro pré-estabelecido por lei.

Não admira, pois, que, com o DL 83/2006 de 3/5 se tenha dado um primeiro passo no sentido apontado, já que o diploma estabeleceu procedimentos obrigatórios de proposta razoável para a regularização do dano material, no sentido da defesa dos interesses das vítimas dos acidentes de viação.

Com o DL 291/2007 de 21/8 deu-se mais um passo, com a transposição para a ordem jurídica portuguesa da $5^{a}$ Directiva Automóvel do Parlamento Europeu e do Conselho Europeu (Directiva n ${ }^{\circ}$ 2005/14/CE de 11/5), com vista

1 Palestra efectuada em 20 de Outubro de 2009 no Centro de Formação Jurídica e Judiciária da Região Autónoma Especial de Macau, integrada na Conferência sobre Administração da Justiça e Responsabilidade Civil nos 10 anos da Região Administrativa Especial de Macau.

2 Juiz Conselheiro jubilado do Supremo Tribunal de Justiça 
à regularização de sinistros rodoviários, no que toca ao dano corporal. Foi esta a primeira vez em que, entre nós, este dano se autonomizou.

Consequentemente, o DL 352/2007 de 23/10 veio introduzir na ordem jurídica portuguesa a Tabela de Avaliação de Incapacidades Permanentes em Direito Civil e a Portaria $n^{\circ} 377 / 2008$ de 26/5, complementando-o, estabeleceu os valores orientadores de proposta razoável para indemnização do dano corporal resultante de acidente de automóvel. E, mais recentemente, a Portaria $n^{\circ} 679 / 2009$ de 25/6 veio actualizar os valores daquela, de acordo com o índice de preços ao consumidor de 2008, do mesmo passo que corrigiu uma lacuna existente na fórmula de cálculo dos danos patrimoniais futuros e alargou o direito indemnizatório por esforços acrescidos a lesados ainda sem actividade profissional habitual e reviu extraordinariamente o montante da indemnização por incapacidade permanente absoluta para o jovem que não iniciou vida laboral.

Estes são, sem dúvida, passos importantes, mas o quadro ainda não está completo. Temos de nos aproximar mais do "guia barème" europeu. Os "valores orientadores" apenas reflectem a posição de quem está obrigado a indemnizar. Os juízes não devem lançar mão destas tabelas. Quando muito servirão para comparar em simulações com o cálculo que antes era feito. Daí que considere que se mantém actual o meu estudo publicado na CJ em 2001.

\section{Os vários aspectos da realidade "dano"}

Os danos indemnizáveis são, como se sabe, patrimoniais e não patrimoniais. Mas a realidade "dano" ou "prejuízo", consagrado desde logo no art.564" do Código Civil Português (CCP), aparentemente simples, surge na prática sob vários aspectos ou subrealidades, por vezes confundidas. Com efeito, na norma legal o dano compreende o prejuízo causado (dano emergente) e os benefícios que o lesado deixou de obter em consequência da lesão (lucro cessante) - art. $564^{\circ} \mathrm{n}^{\circ} 1$ - para além dos danos futuros $\left(\mathrm{n}^{\circ} 2\right)$.

Há uma aparente omissão do dano corporal. Ora este pode surgir na sua expressão máxima, ofendendo o bem jurídico "vida" ou, mais atenuadamente, ofendendo tão só a "integridade física”; mas esta, por sua vez, pode apresentar-se em vários graus, inclusive o grau máximo - incapacidade total - que em certos casos (ex. vida vegetativa, estado de coma) praticamente se equipara à morte. Iremos vendo onde se encontra "escondido" na lei o dano corporal.

Fazendo um zoom sobre a realidade "dano", como o fez o Ac. do STJ de 28/X/92 (CJ Ano XVII, T4, p. 28 e ss.), podemos encontrar os seguintes aspectos: 
1. Danos emergentes, os quais incluem os prejuízos directos e as despesas directas, imediatas ou necessárias;

2. Ganhos cessantes;

3. Lucros cessantes;

4. Custos de reconstituição ou reparação;

5. Danos futuros;

6. Prejuízos de ordem não patrimonial.

Os prejuizos directos traduzem-se na perda, destruição ou danificação de um bem, que tanto pode ser um objecto, como um animal ou uma parte do corpo do lesado ou o próprio direito à vida deste; as despesas necessárias ou imediatas correspondem ao custo de prestação dos serviços alheios necessários quer para prestar o auxílio ou assistência quer para eliminar aspectos colaterais decorrentes do acto ilícito, aspectos estes que abrangem realidades tão diversificadas como a limpeza do local, reboques de viaturas ou o enterro de quem tenha falecido.

Os ganhos cessantes correspondem à perda da possibilidade de ganhos concretos do lesado, incluindo-se na categoria de lucros cessantes. Mas esta perda não deve ser confundida: a) com a perda de capacidade de trabalho, que é nitidamente um dano directo, que se pode aferir em função da tabela nacional de incapacidades; b) nem com a perda da capacidade de ganho, que é o efeito danoso, de natureza temporária ou definitiva que resulta para o ofendido do facto de ter sofrido uma dada lesão impeditiva da obtenção normal de determinados proventos certos, em regra até ao momento da reforma ou da cessação da actividade como paga do seu trabalho, e que se inclui na categoria dos prejuízos directos, embora com uma importante vertente de danos futuros; c) nem ainda com a perda efectiva de proventos futuros de natureza eventual, ainda que em vias de concretização, que se inclui na categoria de lucros cessantes; d) nem, finalmente, com a perda que possa resultar do eventual desaparecimento de uma situação de trabalho produtora ou potencialmente produtora de ganhos, que também se inclui na categoria de lucros cessantes.

Os custos de reconstituição ou de reparação correspondem ao preço dos bens ou serviços necessários para proceder a uma correcta reparação, quando tal seja possível, do objecto, animal, ou da parte do corpo ou órgão destruídos ou danificados, e compreende, por ex. os preços de oficina, de hospitalização, de operações cirúrgicas e até de eventuais próteses que se torne necessário efectuar, motivo pelo qual existe uma estreita relação entre eles e o campo dos danos ou prejuízos directos, mas sem que as duas realidades se confundam.

Os danos futuros compreendem os prejuizos que, em termos de causalidade adequada, resultaram para o lesado (ou resultarão de acordo com os dados pre- 
visíveis da experiência comum) em consequência do acto ilícito que foi obrigado a sofrer, ou, para os chamados "lesados em $2^{\circ}$ grau" da ocorrência da morte do ofendido em resultado de tal acto ilícito, e ainda os que poderiam resultar da hipotética manutenção de uma situação produtora de ganhos durante um tempo mais ou menos prolongado, (e que poderá corresponder, nalguns casos ao tempo de vida laboral útil do lesado), e compreendem ainda determinadas despesas certas, mas que só se concretizarão em tempo incerto (ex. substituição de uma prótese ou futuras operações cirúrgicas).

Os danos morais ou prejuízos de ordem não patrimonial são prejuízos insusceptíveis de avaliação pecuniária porque atingem bens que não integram o património do lesado (a vida, a saúde, a liberdade, a beleza). Não devem confundir-se com os danos patrimoniais indirectos, isto é, aqueles danos morais que se repercutem no património do lesado, como o desgosto que se reflecte na capacidade de ganho diminuindo-a, pois esta constitui um bem redutível a uma soma pecuniária.

Porque estes danos não atingem o património do lesado, a obrigação de os ressarcir tem mais uma natureza compensatória do que indemnizatória, sem esquecer, contudo, que não pode deixar de estar presente a vertente sancionatória (Prof. A. Varela, Das Obrigações em Geral, 1º, $9^{\mathrm{a}}$ ed. p. 630). Com efeito, em termos de dinheiro em quanto se pode avaliar a vida, as dores físicas, o desgosto, a perda da alegria de viver, uma cicatriz que desfeia?

O chamado dano de cálculo não serve para aqui. Por isso a lei lançou mão de uma fórmula genérica, mandando atender só àqueles danos não patrimoniais que, pela sua gravidade, mereçam a tutela do direito (art. $496^{\circ} \mathrm{n}^{\circ} 1$ do CCP). Gravidade que deve ser apreciada objectivamente, ainda segundo o ensino do saudoso Prof. Varela (obra cit. p. 628). Por outro lado, a lei remete a fixação do montante indemnizatório por estes danos para juízos de equidade, haja culpa ou dolo ( $\operatorname{art.} 496^{\circ} \mathrm{n}^{\circ} 3$ ), tendo em atenção os factores referidos no art. $494^{\circ}$ [grau de culpabilidade do agente, situação económica deste e do lesado e quaisquer outras circunstâncias. (Entre estas, para norma semelhante, costumam a doutrina e jurisprudência francesas apontar a idade e sexo da vítima, a natureza das suas actividades, as incidências financeiras reais, possibilidades de melhoramento, de reeducação e de reclassificação - Françoise Cocral, Les responsabilités civiles diverses et le contrat d'assurance)]. Assim, o julgador deve ter em conta todas as regras de boa prudência, do bom senso prático, da justa medida das coisas e da criteriosa ponderação das realidades da vida, sem esquecer a natureza mista da reparação, pois visa-se reparar o dano e também punir a conduta. Cumpre aqui ainda salientar que a velha distinção feita por M. Andrade entre culpa lata, leve e levíssima (Teoria Geral das Obrigações, $2^{\mathrm{a}}$ ed. P. 341-342) mantém actualidade, como expressam P. Lima e A. Varela (CC anot. $1^{\circ}$ p. 497). 
Independentemente do que fica dito, com o DL 352/07 e as Portarias $\mathrm{n}^{\circ}$ 377/08 e 679/09, alguns dos danos não patrimoniais já estão pré- estabelecidos nas tabelas. ${ }^{3}$

\section{Indemnização por danos patrimoniais}

Rege, quanto a estes, como se sabe, em primeira linha, o princípio da reposição natural, expresso no art. $562^{\circ}$ do CCP. E quando esta não for possível, bastante ou idónea $\left(\operatorname{art} .566^{\circ} \mathrm{n}^{\circ} 1\right)$, há que lançar mão da indemnização em dinheiro, a fixar de acordo com a teoria da diferença (art. $566^{\circ} \mathrm{n}^{\circ} 2$ ), segundo a qual a indemnização tem como medida, em princípio, a diferença entre a situação patrimonial real do lesado na data mais recente que puder ser atendida pelo tribunal e a situação hipotética que teria nessa data, se não tivesse ocorrido o facto lesivo gerador do dano. Essa data mais recente a ser atendida é a do encerramento da discussão (art. $663^{\circ}$ do CPC Português). Este preceito é aplicável ao julgamento pelo Tribunal da Relação perante o qual se reabre, dentro de certos limites, a discussão da matéria de facto, por força do disposto no art. $713^{\circ} \mathrm{n}^{\circ} 2$ do referido $\mathrm{CPCP}^{4}$.

Vejamos agora, em panorâmica, a indemnização destes danos, detendo-nos mais de perto na problemática dos danos futuros.

\section{A) Danos emergentes}

O cálculo destes danos obedece, em princípio, a uma pura operação aritmética. Assim acontece, por ex. com as despesas hospitalares, transporte em ambulância, despesas médicas e medicamentosas, despesas de funeral, etc. Mas há um aspecto particular a ter em conta. É que a perda de um membro ou de uma parte do corpo em resultado de um acidente de viação, por ex., é indemnizável como dano emergente (para além, evidentemente, de ter de ser encarado na sua vertente de dano futuro). Como se opera, neste caso, a indemnização face à norma aparentemente redutora do $\mathrm{n}^{\circ} 1$ do art. $564^{\circ}$ do $C C P{ }^{5}$ E se do acidente resultou, por ex. a perda do baço, uma disfunção

3 Mais adiante abordarei este tema que me é caro, já que fiz parte do grupo de trabalho que ao longo de 13 anos pugnou para que a ordem jurídica portuguesa acolhesse o sistema das tabelas visando uma mais fácil avaliação do dano corporal. Mas não estas tabelas da Portaria.

4 Cfr. Ac. do STJ de 6/3/2000, $7^{\text {a }}$ secção.

5 Redutora porque reduz tudo ao aspecto patrimonial: "os danos emergentes correspondem aos prejuízos sofridos ou seja à diminuição do património do lesado” (P. Lima e A. Varela, CC anot. $1^{\circ}$, p. 579). 
sexual ou mesmo a impotência só haverá lugar a indemnização por danos não patrimoniais?

Foi precisamente para obviar a situações destas que o grupo de trabalho atrás referido procurou que o dano corporal, susceptível de uma tripla avaliação, se tornasse independente e saísse da gaveta para onde o legislador o remeteu e onde permanecia envergonhadamente escondido. É que o dano corporal deve ser visto: 1) como dano não patrimonial, na sua vertente de dano moral e estético ou enquanto gerador de esforços acrescidos para manutenção do mesmo rendimento; 2) ou como dano patrimonial futuro, sempre que seja gerador de rebate profissional concreto, ocasionando perda dos rendimentos do trabalho; 3) ou como dano a se, biológico, enquanto violação do direito ou ofensa à integridade físio-psíquica.

Ora o dano corporal é tratado na legislação civil portuguesa, em primeira linha na esfera dos danos não patrimoniais e depois em parte e apenas reflexamente no campo patrimonial. Pois bem. Mantendo-se embora estas vertentes patrimonial e não patrimonial, claramente indemnizáveis, o que se fez foi autonomizar o dano corporal também naquele apontado tertium genus biológico, logo também indemnizável.

Países como Espanha, França e Itália resolveram o problema recorrendo a tabelas ou barèmes, como atrás referi, onde são escalpelizados todos os danos corporais, e alguns marcadamente não patrimoniais mas que se podem quantificar (ex. o quantum doloris e o prejuízo estético), outros absolutamente não patrimoniais (ex. perda do direito à vida, sofrimento sofrido pela vítima antes de falecer, sofrimento dos familiares). Ficam de fora os danos patrimoniais que, por serem avaliados em concreto, não são baremizáveis (permita-se-me o neologismo) e os restantes danos não patrimoniais. ${ }^{6}$

Hoje, a problemática da avaliação e indemnização do dano corporal, na sua tripla vertente, está resolvida (em minha opinião mal resolvida), à luz das tabelas constantes dos diplomas legais atrás citados e que, mais adiante, veremos em pormenor.

Note-se que a Portaria $n^{\circ} 377 / 2008$ na conjugação dos arts. $2^{\circ}$ als. c) e d), $3^{\circ}$ als. b), c) e d) e $10^{\circ} \mathrm{n}^{\circ} 1$ já estabelece que a proposta razoável relativamente aos danos patrimoniais emergentes deve contemplar o pagamento integral dos rendimentos perdidos, decorrentes da incapacidade temporária do lesado e que sejam fiscalmente documentáveis, bem como das despesas médicas e medicamentosas, refeições, estadas e transportes, desde que sejam apresentados os originais dos respectivos comprovativos, o dano biológico e as perdas salariais.

6 O Parlamento Europeu aprovou em Junho de 2004 o "Barème médical européen d'évaluation des atteintes à l'intégrité physique et psyquique". 
E o $\mathrm{n}^{\circ} 2$ do art. $10^{\circ}$ estatui que nos casos de auxílio de terceira pessoa, adaptação de veículo ou de residência, consideram-se como valores de referência, os constantes do anexo V.

\section{B) Lucro cessante}

Neste incluem-se os benefícios que o lesado deveria ter obtido e não obteve. Logo se percebe que o cálculo destes danos é uma operação delicada, de difícil solução, porque obriga a ter em conta a situação hipotética em que o lesado estaria se não houvesse sofrido a lesão, o que implica uma previsão, pouco segura, sobre dados verificáveis no futuro. Por isso é que este tipo de danos deve ser calculado segundo critérios de probabilidade ou de verosimilhança, de acordo com o que, em cada caso concreto, poderá vir a acontecer, pressupondo que as coisas seguem o seu curso normal; e se mesmo assim não puder apurar-se o seu valor exacto, o tribunal dever julgar segundo a equidade. ${ }^{7}$

\section{C) Danos futuros}

Considerando o disposto no DL 352/07 e no relatório preambular da Portaria no 377/08, há duas notas a destacar: a) um dos princípios basilares é que só há lugar à respectiva indemnização quando a situação incapacitante do lesado o impede de prosseguir a sua actividade profissional habitual ou qualquer outra (caso de impossibilidade de reconversão); b) ainda que não tenha direito à indemnização por dano patrimonial futuro, em situação de incapacidade permanente parcial, o lesado terá direito à indemnização pelo seu dano biológico. Não entendo esta distinção nem para ela encontro justificação. Por isso, repito, os juízes não devem socorrer-se destas tabelas para fixar indemnizações.

1 - Caso de morte: "São indemnizáveis, em caso de morte os danos patrimoniais futuros daqueles que, nos termos do CC, podiam exigir alimentos à vítima, ou aqueles a quem esta os prestava no cumprimento de uma obrigação natural" (art. $2^{\circ}$ al. b) da Portaria.

A proposta razoável para esta indemnização obedece à seguinte regra: o dano patrimonial futuro é calculado de acordo com as regras constantes do Anexo III (art. $6^{\circ} \mathrm{n}^{\circ} 1$ a) da Portaria). Este anexo apresenta a seguinte fórmula de cálculo:

7 Cfr. Ac. do STJ de 10/2/98 e a doutrina nele citada, in Colectânea de Jurisprudência, STJ, 1998, T1, p. 67. 
$\left.\mathrm{DPF}=\left((1+\mathrm{i})^{\wedge} \mathrm{n}-1\right) /(1+\mathrm{i})^{\wedge} \mathrm{n} x \mathrm{i}\right) x \mathrm{p}$, sendo $\mathrm{i}=((1+\mathrm{r}) /(1+\mathrm{k}))-1 ; \mathrm{p}=$ prestações (rendimentos anuais); $\mathbf{r}$ taxa de juro nominal líquida das aplicações financeiras $=5 \% ; \mathbf{k}$ a taxa anual de crescimento da prestação $=2 \%$; e $\mathbf{n}$ o número de anos pelo qual a prestação é devida. ${ }^{8,9}$

E tal como a jurisprudência já vinha entendendo, haverá que deduzir aos rendimentos aquilo que a vítima gastaria consigo mesma, isto é, 1/3, já que as 7 situações constantes do $\mathrm{n}^{\circ} \mathbf{2}$ do anexo III só beneficiam as seguradoras e não têm qualquer justificação. Prejudicam os lesados e levam à fixação de indemnizações inferiores àquelas a que se chegava anteriormente. Basta que o julgador faça as simulações entre o "antes" e o "agora". Se concluir que a forma de cálculo anterior é mais favorável ao lesado, é esta que deve ser aplicada.

Para cálculo do tempo durante o qual a prestação se considera devida, presume-se que a vítima se reformaria aos 70 anos (al. b) do $\mathrm{n}^{\circ} 1$ do art. $6^{\circ}$ ).

Para se apurar o rendimento mensal da vítima, a lei prevê 3 situações: a) em casos normais, são considerados os rendimentos líquidos auferidos à data do acidente fiscalmente comprovados $\left(\mathrm{n}^{\circ} 2\right.$ do art. $\left.6^{\circ}\right)$; b) em relação a vítimas que não apresentem declaração de rendimentos, não tenham profissão certa ou cujos rendimentos sejam inferiores à RMMG (retribuição mensal mínima garantida), é considerada esta, à data da ocorrência para apuramento dos rendimentos $\left(\mathrm{n}^{\circ} 3\right.$ - assim se dando forma de lei à ficção elaborada pela jurisprudência); c) se a vítima estiver em idade laboral, tiver profissão, mas encontrando-se numa situação de desemprego, é considerada a média dos últimos 3 anos de rendimentos líquidos declarados fiscalmente, majorada de acordo com a variação do índice de preços ao consumidor (total nacional, excepto habitação), nos anos em que não houve rendimento, ou o montante mensal recebido a título de subsídio de desemprego, consoante o que for mais favorável ao beneficiário $\left(\mathrm{n}^{\circ} 4\right)$.

Vamos agora proceder a uma simulação entre a forma de cálculo da indemnização por mim defendida no meu artigo sobre dano corporal, (publicado em 2001 na CJ -STJ, I, p. 11 e ss.) e a fórmula actual. Imaginemos a seguinte situação: Homem, 40 anos, casado com filhos de idade menor ou igual a 18 anos, vítima mortal, com o rendimento mensal de $2.000 €$.

O rendimento anual é de $28.000 €(2.000 \times 14$ meses $)$.

Gastaria consigo mesmo $1 / 3$, ou seja $9.333 €$; o restante $-18.667 €-$ seria o seu contributo para a família (rendimento perdido). Há que apurar qual o

8 Os factores constantes da tabela do Anexo são já o resultado da aplicação da fórmula, com excepção da variável "p". Assim, sabendo-se a idade do lesado, sabe-se o prazo e o factor, que será multiplicado por "p".

9 Todas as referências à Portaria sem menção de no consideram-se feitas à Portaria nº 377/08. 
capital necessário para, a determinado juro, se encontrar aquele rendimento perdido. Experimentemos com o juro de 1\% (juro actual do BCE):

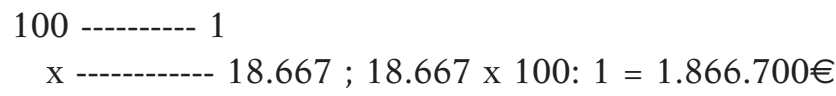

Agora, há que descontar $1 / 3$ ou 1/4 porque a família recebe, de uma só vez, o capital e assim se obviará ao enriquecimento injustificado à custa alheia.

Com o desconto de 1/3: $1.866 .700: 3=622.233 ; 1.866 .700-622.233=1.244 .467$ Com o desconto de $1 / \$: 1.866 .700: 4=466.675 ; 1.866 .700-466.675=1.400 .025$ Fazendo a média: $1.244 .467+1.400 .025: 2=1.322 .246$.

Atendendo à idade arredondaria para 1.350.000€.

Vamos fazer outra operação, para avaliarmos se este montante a que se chegou é ou não desajustado da realidade.

A vítima teria mais 30 anos de vida activa. Como auferia $28.000 €$ /ano, pressupondo que o seu rendimento se mantinha sem alterações, ao fim de 30 anos auferiria 840 mil euros. A discrepância entre este valor e aquele outro é enorme, mesmo considerando actualizações salariais. Então, vamos simular com um juro de $2 \%$ (até porque a tendência, segundo indicações do BCE, é para a subida para fins do corrente ano de 2010).

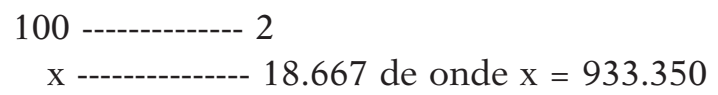

O desconto de 1/3 dará 311.116; logo 933.350 - 311.116 = 622.234

O desconto de 1/4 dará 233.337; logo $933.350-233.337=700.013$

Média: $622.234+700.013: 2=661.123$.

Vejamos de seguida como se passam as coisas à luz das tabelas (Anexo III).

Como a vítima tinha 40 anos, o prazo até à reforma é 30 anos. Segundo a tabela, o factor é 20, 331212. Então, 28.000€ x 20,331212 = 569.273,93€.

Mas agora há que descontar aquilo que a vítima gastaria consigo e que, no nosso caso, será $20 \%$, de acordo com a percentagem de abatimento constante do $n^{\circ} 2$ do Anexo.

$20 \%$ de 569.273,93 são $113.854,78$. Então, 569.273,93 - 113.854,78 = 455.419,15€

Esta seria a quantia que a família da vítima receberia a título de danos patrimoniais futuros, daqui se concluindo que a aplicação das tabelas é mais desfavorável à vítima.

Considerando os montantes a que cheguei, afastaria de todo, por desajustados, os operados com o juro a $1 \%$ e com as tabelas. Consideraria justa uma indemnização entre 700 mil e 750 mil euros. 
2 - Caso de incapacidades: As conclusões a que cheguei no caso de morte são as mesmas para o caso das incapacidades. A aplicação das tabelas prejudica os lesados.

E no caso das incapacidades parciais permanentes (IPP) o julgador nem sequer pode fazer simulações, porque o perito médico não lhe dará a percentagem de incapacidade, que tem tendência para acabar, mas tão só as pontuações. A pontuação não equivale à percentagem de incapacidade. Os pontos são unidades de apreciação, logo o juiz é livre de apreciá-los, tão livre como o perito médico, podendo aquele saltar para fora dos limites estabelecidos nas tabelas. Daí também que um perito médico possa, perante certos danos corporais (biológicos), atribuir determinada pontuação e outro, perante um caso semelhante, atribuir pontuação diferente. É que as pontuações dependem de vários factores, por ex. lesões sinérgicas e não sinérgicas.

A filosofia subjacente às tabelas com as pontuações é a protecção das grandes incapacidades e a pouca valorização das pequenas. Há mesmo países em que as pequenas incapacidades não são sequer consideradas. Mas com estas tabelas é caso para dizer "nem tanto ao mar nem tanto à terra"...

Posto este intróito, são indemnizáveis os danos patrimoniais futuros, nas situações de incapacidade permanente absoluta ou de incapacidade para a profissão habitual, ainda que possa haver reconversão profissional (art. $3^{\circ}$ al. a) da Portaria $377 / 08$ de $26 / 5$ ).

a) incapacidade permanente absoluta (IPA): À semelhança da situação "morte", o dano patrimonial futuro é calculado de acordo com a fórmula constante do anexo III ( ${ }^{\circ} 1$ al. a) do art. $\left.7^{\circ}\right)$, para o cálculo do tempo do dever de prestar, presume-se a idade de reforma aos 70 anos (al. b) e para o apuramento do rendimento mensal aplicam-se as regras dos $\mathrm{n}^{\circ} \mathrm{s} 2$ a 4 do art. $6^{\circ}$.

Nas situações de incapacidade permanente absoluta para a prática da profissão habitual, sem possibilidade de reconversão para outras profissões dentro da sua área de formação técnico-profissional, a proposta indemnizatória corresponde a $2 / 3$ do capital calculado de acordo com a fórmula aludida ( ${ }^{\circ}$ 2 do art. $7^{\circ}$ ). São equiparadas a estas, as situações em que os lesados, de idade igual ou superior a 65 anos, com incapacidade permanente absoluta para a prática da profissão habitual, ainda que possam reconverter-se profissionalmente $\left(\mathrm{n}^{\circ} 4\right)$.

Nas situações de incapacidade permanente absoluta para a prática da profissão habitual, embora com possibilidade de reconversão, a proposta indemnizatória corresponde a 4 anos de rendimentos líquidos.

Note-se ainda que, nestas situações de IPA, o legislador prevê, preferencialmente, a indemnização sob a forma de renda, relativamente aos lesados 
com idade inferior a 25 anos e/ou de incapacidades iguais ou superiores a $60 \%$ (art. $11^{\circ}$ da Portaria).

Vamos agora efectuar operações de simulação, com os mesmos dados anteriores.

Estamos no âmbito da IPA. Como o lesado teria mais 30 anos de vida profissional activa, como já vimos antes, 28.000 × 30 anos $=840.000 €$.

Não há que proceder à dedução de $1 / 3$ porque o lesado não morreu. Mas há que deduzir $1 / 3$ ou $1 / 4$ para evitar o enriquecimento injusto.

Com 1/3: $840.000-1 / 3(280.000)=560.000$

Com 1/4: $840.000-1 / 4(210.000)=630.000$

Média: $560.000+630.000: 2=595.000$

Neste caso estabeleceria o montante indemnizatório em 600.000€.

Vejamos como se passam as coisas aplicando as tabelas.

=> IPA sem possibilidade de reconversão: A indemnização corresponde a 2/3 do capital calculado de acordo com a fórmula do Anexo III (art. $7^{\circ}$ $\mathrm{n}^{\circ} 2$ da Portaria $\left.\mathrm{n}^{\circ} 377 / 08\right)$.

Como se viu atrás, em caso de morte, a aplicação da fórmula conduzia ao montante indemnizatório de 569.273,93€. 2/3 deste valor são 379.515,96€.

Também aqui se chega a uma indemnização mais desfavorável para o lesado.

=> IPA com possibilidade de reconversão: A indemnização corresponde a 4 anos de rendimentos líquidos (art. $7^{\circ} \mathrm{n}^{\circ} 3$ da Portaria). Assim, temos de saber qual o rendimento líquido e depois multiplicá-lo por 4. Vamos supor, por mero exercício exemplificativo, que o rendimento líquido do lesado era de $25.000 €$. O total seria $100.000 €$.

Manter-se-ia, também aqui, uma posição mais desfavorável para o lesado.

b) incapacidade permanente parcial (IPP): Nesta situação, ainda que não tenha direito à indemnização por dano patrimonial futuro, o lesado terá direito à indemnização pelo seu dano biológico. Assim, o perito médico examina as lesões e atribui-lhes as respectivas pontuações, conforme a Tabela Nacional anexa ao DL 352/07, até fixar o grau de desvalorização. Depois, o cálculo é efectuado de acordo com o anexo IV da Portaria, tendo em conta a idade, reportada à data do acidente (art. $12^{\circ}$ da Portaria) e o grau de desvalorização.

Como acima se disse, aqui não há hipótese de efectuar simulações, porque não nos é dada a percentagem de incapacidade e os pontos são unidades de apreciação.

Vamos, então, exemplificar, de acordo com as tabelas constantes do Anexo IV. 
Suponhamos que o médico atribui ao lesado uma pontuação de 20 pelos danos biológicos que examinou.

Os 20 pontos encontram-se na $1^{\mathrm{a}}$ coluna, $4^{\mathrm{a}}$ posição vertical. E a idade (40 anos) encontra-se na $5^{\mathrm{a}}$ coluna horizontal. Cruzando as duas linhas encontramos os valores do dano biológico, entre um mínimo de1.200,42€ e um máximo de $1.277,37 €$. (valores em euros definidos por ponto - regra 2 do anexo).

De seguida há que considerar as regras expressas na nota 3 do anexo: Deverão considerar-se os pontos mínimo e máximo do intervalo em função da proximidade do caso concreto aos limites para os quais cada intervalo foi construído: (i) o limite máximo corresponde à menor idade e à maior pontuação; (ii) o limite mínimo corresponde à maior idade e à menor pontuação.

No nosso exemplo, 1.200,42€ é atribuído aos casos de 40 anos e 16 pontos; e $1.277,37 €$ aos casos de 36 anos e 20 pontos. Logo, como temos a maior idade e ao mesmo tempo a maior pontuação, afigura-se ajustado fixar na média, ou seja, $1.238,90 €$.

Em seguida este valor é multiplicado por 20 (pontos): $24.778 €$ (regra 2).

Estamos em condições, agora, de aplicar a regra 1 do anexo: os pontos são determinados de acordo com o RMMG (rendimento mensal médio garantido) de 2007. Este foi fixado em $403 €$ pelo art. $1^{\circ}$ do DL 2/2007 de 3/1.

Ora sabendo nós que o rendimento mensal do lesado era de $2.000 €$, basta agora utilizar uma regra de três simples:

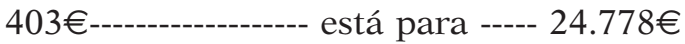

$$
\begin{aligned}
& \text { assim como } 2.000 € \text {--------------- está para ------- X } \\
& \text { de onde } X=24.778 € \text { x } 2.000 €: 403 € ; \operatorname{logo}, 122.967,74 € \text {. }
\end{aligned}
$$

Perante este valor, poderia bem ser arredondado para um entre $125 \mathrm{mil}$ e 130 mil euros.

\section{Indemnização por danos não patrimoniais}

1 - Em caso de morte: Rege, neste aspecto, o art. $5^{\circ}$ da Portaria. À semelhança do que já vinha sendo entendido pela doutrina e pela jurisprudência - esta a partir do longínquo Ac. do STJ de 17/3/71 (BMJ 205 p. 150) - considerando que o art. $496^{\circ}$ do CCP contém três espécies de indemnizações, o legislador plasmou-as no anexo II da Portaria, aí contemplando a indemnização pela dor sofrida pelos familiares (herdeiros) da vítima (A), a dor sofrida pela própria vítima, sendo cada vez maior conforme o tempo de sobrevivência (D) e a perda do direito à vida, diminuindo à medida que a 
idade aumenta (C). ${ }^{10} \mathrm{E}$ acrescentou ainda um outro, devido pela perda de feto. Todos os danos contemplados em A), B) e D) são passíveis de majorações, conforme consta do referido anexo II.

Aqui, afiguram-se-me correctos os valores constantes do Anexo.

2 - Em caso de incapacidades: Dispõe o art. $4^{\circ}$ da Portaria que, além dos direitos indemnizatórios previstos no artigo anterior (situações já atrás referidas), o lesado tem ainda direito a ser indemnizado por danos morais complementares, autonomamente, nos termos previstos no anexo I da presente portaria, nas seguintes situações:

a) por cada dia de internamento hospitalar; b) por dano estético; c) pelo quantum doloris; d) quando resulte para o lesado uma incapacidade permanente absoluta para a prática de toda e qualquer profissão ou da sua profissão habitual; e) quando resulte para o lesado uma incapacidade permanente que lhe exija esforços acrescidos no desempenho da actividade habitual (redacção dada pelo art. $1^{\circ}$ da Portaria $n^{\circ}$ 679/09 de 25/6); f) quando resulte uma incapacidade permanente absoluta para o lesado que, pela sua idade ainda não tenha ingressado no mercado de trabalho e por isso não tenha direito à indemnização prevista na al. a) do art. anterior ${ }^{11}$.

Neste particular suscitam-se-me duas dúvidas: $1^{\text {a }}$ - Será defensável que o quantum doloris fixado até ao grau 3 não seja objecto de qualquer indemnização?; $2^{\mathrm{a}}$ - E que a repercussão na vida laboral apenas seja indemnizável se for superior a 10 pontos?

NOTA: Estas tabelas são apenas orientadoras. Se forem utilizadas, o juiz no seu prudente arbítrio tem o dever de "saltar" para fora dos valores máximos. Não deve ficar "escravo" das tabelas, nunca olvidando o art. $496^{\circ}$ do CC. Caso contrário corre-se o risco de se implantar nas decisões judiciais uma "ditadura das seguradoras".

10 Quanto a esta, acabou-se com a discussão de saber se a indemnização deve ser igual para todos, dado o valor da vida para a vítima enquanto ser, ou se a perda do direito à vida deve ser aferida em função de 3 realidades - vida que se perde com função normal, que desempenha na família e na sociedade; vida que se perde sem função específica na sociedade (criança, doente, inválido) e vida que se perde com função excepcional (sábio, cientista).

11 Recorde-se que esta indemnização se refere aos danos patrimoniais futuros nas situações de incapacidade permanente absoluta ou de incapacidade para a profissão habitual ainda que possa haver reconversão. 


\section{0 caso especial da lesão corporal "impotência"12}

O caso prático, real, levado à discussão no Congresso Internacional sobre Dano Corporal, realizado em Bilbau em 2000, versava um acidente de viação, ocorrido em San Sebastian, em que o lesado, para além de fracturas várias, ficou paraplégico e com impotência coeundi por ausência de erecção. E é sobre este aspecto que irei dar a conhecer o que se discutiu, adiantando desde já que, para os intervenientes dos restantes países, não constituiu problema algum atribuir uma indemnização à mulher do lesado por danos não patrimoniais, por se ver privada de uma vida sexual normal. Para além, claro, de indemnização ao lesado pela impotência, abrangendo os aspectos do dano corporal em si e do dano não patrimonial.

Dada a conhecida sinistralidade rodoviária em Portugal, muitas vezes com graves consequências (paraplegias, tetraplegias), seria de esperar que aparecessem em tribunal situações de impotência, derivadas de acidentes. Mas tal não acontece. Ou porque realmente elas não se verificam ou porque haverá ainda um certo pudor do lesado em vir dizer ao tribunal que ficou impotente. ${ }^{13}$

Na nossa legislação, em relação ao lesado, este dano corporal não seria indemnizável fora da vertente do dano não patrimonial; e quanto à mulher do lesado, ficaria arredada qualquer indemnização.

No referido Congresso, defendi a possibilidade de, mesmo em Portugal, a mulher do lesado ter direito a uma indemnização por danos não patrimoniais pela impotência do marido. O fundamento legal não pode ser o art. $496^{\circ} \mathrm{n}^{\circ}$ 2 do CCP, que pressupõe a morte da vítima. Como me pareceu uma situação de flagrante injustiça, pensei poder-se atingir aquele objectivo percorrendo a via dos direitos de personalidade, encarando a sexualidade como um deles. O débito conjugal tem tanta força que a sua recusa pode ser motivo de divórcio. Ao débito corresponde um direito do cônjuge a ter com o outro um relacionamento sexual normal. Logo, a sexualidade, pelo menos dentro do casamento, pode ser encarada como um direito de personalidade.

Reconheço que este raciocínio pressupõe um olhar diferente sobre a sexualidade e o afastamento da concepção judaico-cristã sobre ela, na medida em que separa sexualidade e fecundidade. Reconheço também que ele pode levantar outras questões: direito à sexualidade também nas uniões de facto?

12 Sigo de perto o meu artigo "Dano corporal em acidentes de viação", publicado nos Acórdãos do STJ, Ano IX, 2001,Tomo I, p. 11).

13 Recentemente, e pela primeira vez em Portugal, o STJ foi chamado a decidir um caso de impotência. Citando o meu artigo, em cuja fundamentação se baseou, o Ac. de 26/5/09 atribuiu à mulher do lesado uma indemnização. 
se é um direito de personalidade, acompanha a pessoa, independentemente do seu estado civil?

Com o DL 352/07 esta questão nem sequer foi abordada, podendo tê-lo sido. Na Tabela Nacional de Avaliação de Incapacidades no Direito Civil, surge apenas (em relação ao homem e para o que agora importa) o dano corporal “perda do pénis" (código Rb0303, valorizada em 40 pontos) e a "disfunção eréctil" (código Rb0501, valorizada entre 5 e 15 pontos). Mas não se prescreveu qualquer indemnização por danos não patrimoniais a favor do cônjuge do lesado. No entanto, algo de positivo já foi feito. Em relação ao lesado pelo menos estes danos corporais autonomizaram-se.

\section{Breve visão sobre o guia-barème europeu aprovado pelo PE}

Penso que se justifica esta ligeira abordagem para uma melhor compreensão, por parte de juízes, advogados e profissionais dos departamentos jurídicos das seguradoras, sempre que tiverem de interpretar os relatórios médicos sobre o dano corporal, dada a novidade da matéria entre nós.

Estruturalmente organizado pela $\mathrm{CEREDOC}^{14}$, que reuniu ensinamentos universitários e profissionais de alto nível de diferentes estados europeus, o documento foi aprovado pelo PE e CE. Nele estão essencialmente plasmadas as grandes incapacidades, deixando-se à consideração de cada país membro a organização, estrutura, elencagem e taxas percentuais das pequenas e médias incapacidades, bem como o estabelecimento da respectiva indexação, esta extensiva às grandes incapacidades, por se tratar de matéria do foro próprio de cada país.

a) Será que se justifica uma avaliação "barémica" europeia do dano corporal? É que há quem critique as tabelas por padecerem de falta de concepção científica, limitando-se a coligir as taxas aceites pelas várias jurisprudências.

Contra esta posição reagiu o PE, considerando que as tabelas têm a vantagem de ser evolutivas, com o progresso das terapias, da readaptação, das técnicas de objectivação e quantificação e dos conhecimentos do futuro dos traumatizados. Por outro lado, no preâmbulo do documento, diz-se haver sequelas idênticas que, de forma idêntica, se repercutem na vida quotidiana, logo justificando uma avaliação idêntica. Assim, essas sequelas podem responder a uma lógica barémica.

${ }^{14}$ Confédération Européenne d'Experts en Réparation et Évaluation du Dommage Corporel 
Mas também ali se acentua que a avaliação dos danos corporais com recurso a tabelas não se esgota na simples descrição dos danos. "A transposição dessa descrição para o juiz, no plano da indemnização, é um acto interpretativo. E toda a interpretação comporta um risco de alteração, sobretudo se a descrição feita pelo perito num dos Estados membros é utilizada pelo juiz num outro Estado. Os problemas linguísticos e de terminologia específica não podem ser subestimados”. É assim necessário que o perito fundamente aquela descrição. O sistema de taxas de avaliação obriga, portanto, a construir uma tabela com uma finalidade de igualdade e de justiça: para sequelas idênticas, taxa e reparação idênticas. Não se justifica que, numa Europa sem fronteiras, a perda dos mesmos órgãos e das mesmas funções, as mesmas sequelas sejam avaliadas de forma diferente. A avaliação feita por peritos diferentes em diferentes países, conduzindo a conclusões idênticas face a relatórios sobre idênticas sequelas, impõe a utilização de um único "barème” europeu.

\section{b) Linhas mestras}

$1^{\mathrm{a}}$. A afectação da integridade física e psíquica (AIFP) é a redução definitiva do potencial físico e/ou psíquico medicamente constatável ou explicável, à qual se juntam as dores e as repercussões psíquicas que o médico sabe estarem normalmente ligadas à sequela, assim como as consequências na vida diária habitual e objectivamente ligadas a essa sequela.

$2^{\text {a }}$ A taxa de AIFP é a ordem de grandeza em relação a um máximo teórico de $100 \%$ da dificuldade que sofre todo o sujeito cujas sequelas são assim quantificadas, no que toca à efectivação dos gestos e actos habituais da vida quotidiana extra profissional, isto é, a ordem de grandeza da sua incapacidade pessoal.

$3^{\mathrm{a}}$. A percentagem de AIFP não é uma unidade de medida mas uma unidade de apreciação, resultado da integração de medidas de fenómenos diversos, com a ajuda de vários instrumentos, logo expressos em unidades diversas, e por uma opinião intuitiva fortalecida pela experiência e arte de apreender os imponderáveis.

$4^{\mathrm{a}}$. A baremização não exclui uma certa personalização, pois o perito médico tem que explicar as repercussões das sequelas na vida diária do lesado e só depois fixa a taxa.

$5^{\mathrm{a}}$. Em caso de estado anterior patológico modificado pelo acidente objecto da perícia, a descrição e a explicação são complementos indispensáveis da taxa que só tem valor relativo. O dano é a diferença, na vida quotidiana, antes e depois do acidente, diferença que deve estar descrita. 
$6^{\mathrm{a}}$. Os danos particulares específicos da vítima devem, por vezes, estar reconhecidos: prejuízo estético, sexual, dores excepcionais, ofensas às actividades específicas de lazer etc.

$7^{\mathrm{a}}$. Certas taxas propostas (por ex. para a perda de um olho ou nefrectomia unilateral) supõem que uma eventual deterioração do órgão par restante poderá ser tomada em conta, posteriormente, em caso de agravamento do dano.

\section{c) Modo de emprego do guia-barème europeu}

=> O barème europeu é um guia que fornece taxas "pivot" importantes para as ofensas a cada órgão e a cada função. E é suficientemente detalhado para ser no futuro eventualmente utilizado como barème de referência nos seguros pessoais. ${ }^{15}$

=> O guia-barème não contém uma fórmula pseudo-matemática, mas apela ao bom senso clínico e ao realismo do perito médico, tendo em conta estes 3 parâmetros:

1. Em caso de lesões simultâneas em diversos níveis do mesmo membro ou órgão, a taxa global não é a soma das taxas isoladas, mas a resultante da sua sinergia (isto é, quando as sequelas participam na mesma função ou concorrem para ela), não podendo, neste caso, ultrapassar a taxa correspondente à perda total do membro ou órgão.

2. Tratando-se de lesões simultâneas sinérgicas, tocando membros ou órgãos diferentes, é a ofensa global da função que deve ser avaliada.

3. No caso de invalidezes múltiplas não sinérgicas, a taxa global tem que ser inferior à soma das taxas isoladas. Com isto se evita que o tecto de $100 \%$ seja frequentemente ultrapassado, enquanto o lesado conservar alguma capacidade manifesta.

=> O guia-barème não fornece números exactos, mas impõe uma aproximação clínica das sequelas e a análise das suas consequências objectivas na vida quotidiana.

=> O barème é um guia sem carácter imperativo, uma vez que o seu carácter simplesmente indicativo deve ser sublinhado quando se trata de fixar uma taxa de AIFP muito elevada.

=> Sistemática e imperativamente, em caso de sequelas graves, a taxa deve ser fundamentada.

15 Está dividido em 10 capítulos, correspondendo às grandes incapacidades em 10 sistemas: nervoso, sensorial e estomatologia, osteo-articular, cardio-respiratório, vascular, digestivo, urinário, reprodutivo, glandular endócrino e cutâneo. 
Resumo: Avaliação e reparação do dano patrimonial e não patrimonial (no domínio do Direito Civil) Os vários aspectos sob que pode ser encarado o dano. Dificuldades na avaliação de danos patrimoniais futuros e dos não patrimoniais. 0 recente estabelecimento na ordem jurídica portuguesa da Tabela Nacional de Avaliação das Incapacidades Permanentes em Direito Civil e as Portarias com os quadros dos valores orientadores para as indemnizações autonomizaram o dano corporal, sobretudo na sua vertente de dano biológico, e vieram facilitar a avaliação dos danos e a fixação de indemnizações no campo onde antes se verificavam as dificuldades. No caso especial do dano corporal "impotência", o cônjuge tem direito a uma indemnização por danos morais. 0 guia-barème europeu aprovado pelo PE: justificação, linhas mestras e modo de emprego.

Palavra-chave: Dano; dano corporal e biológico; indemnização; tabelas de incapacidade; impotência/indemnização ao cônjuge; guia-barème do PE.

Summary: Evaluation and compensation of patrimonial and moral damage (in civil law) The several points of view of damage. Difficulties in future patrimonial and moral damage evaluation. The new portuguese laws, one establishing a guide-table of bodily damage and another one with values guiding in civil law made autonomus the bodily damages, mainly the biological damage, and, on the other hand, made easier the damages evaluation and establishing the exact amount for the compensation where there was difficulties before. In the special case of bodily damage "impotence", the consort has right of compensation by moral damage. The European guide-table: justification, main lines and instructions for use.

Key-words: Damage; body and biological damage; compensation; table-guide; impotence/compensation to the consort; table-guide of the European Parliament.

Résumé: Évaluation et indemnisation du dommage patrimonial et moral (en droit civil) Les divers aspects du dommage. Difficultés dans l'évaluation des dommages patrimoniaux futurs et des dommages morales. Le récent établissement dans la structure juridique portugaise du Barème National d’ Évaluation des Incapacités Permanentes en Droit Civil et les lois avec les tableaux des valeurs qui déterminent les indemnisations ont rendu autonome le dommage corporel, surtout le dommage biologique et ont rendu facile l'évaluation des dommages et la fixation des indemnisations où avant il y avait des difficultés. Dans le cas spécial du dommage corporel «impuissance», le conjoint a droit à une indemnisation par dommage moral. Le guide-barème européen approuvé par le PE : justification, lignes principales et mode d'emploi.

Mots-clés: Dommage; dommage corporel et biologique; indemnisation; tables d'incapacité; impuissance/indemnisation au conjoint; guide-barème do $\mathrm{PE}$.

\section{Pedido de separatas:}

JOAQUIM JOSÉ DE SOUSA DINIS

soudinis@gmail.com 